\title{
Special issue: Optimization in natural resources, environment and sustainability
}

\author{
Sandra D. Eksioglu ${ }^{1} \cdot$ Sauleh Siddiqui ${ }^{2} \cdot \mathrm{Yu} \mathrm{Wei}^{3}$
}

Received: 18 November 2021 / Accepted: 17 January 2022 / Published online: 7 February 2022

(c) The Author(s), under exclusive licence to Springer-Verlag GmbH Germany, part of Springer Nature 2022

The focus of this special issue of Optimization Letters is to highlight recent advances in operations research, systems analysis, and management science to the study of natural resources, environment, and sustainability. The goal is to share best practices that lead to sustainable management of natural resources, such as, forest, land, and agricultural products, which are vital for the wellbeing of humanity.

This special issue contains 7 papers. The topics covered in these papers are forest planning and wildlife corridors (Yemshanov et al.), wildfire burn scar encapsulation (Durante et al.), planning for biomass cofiring (Dundar et al.), contract design for cellulosic biofuel enterprise (Tokcaer et al.), siting of renewable power generation assets (Berger et al.), process optimization in integrated biorefinery (Gulcan et al.), and refueling station location problem (Abbaas and Ventura).

We would like to thank the authors for their submissions, and the reviewers for their timely and constructive feedback during the editing process. We also would like to thank the Editors-in-Chief of Optimization Letters, Dr. O. Prokopyev and Dr. Krokhmal for their continuous support.

We hope that this special issue will lead to an improved understanding of pressing issues related to natural resources, and environment; and the development of sustainable solutions complex problems faced by our society.

Publisher's Note Springer Nature remains neutral with regard to jurisdictional claims in published maps and institutional affiliations.

Guest editors: Sandra D. Eksioglu, Sauleh Siddiqui, Yu Wei.

\footnotetext{
$凶$ Sandra D. Eksioglu sandra@uark.edu

1 University of Arkansas Fayetteville, Fayetteville, AR, USA

2 American University, Washington, DC, USA

3 Colorado State University Fort, Collins, CO, USA
} 